\title{
DISTRIBUTION AND POPULATION STATUS OF A CRITICALLY ENDANGERED TREE SPECIES Dipterocarpus bourdillonii BRANDIS IN CENTRAL WESTERN GHATS
}

\author{
H. Puttaswamy*, C.G. Kushalappa, K.V. Ajayan and B.N. Sathish \\ College of Forestry, Ponnampet, Karnataka, India \\ E-mail-puttaswamith@gmail.com, Tel-+91 9972845176
}

\begin{abstract}
In the family Dipterocarpaceae, the genus Dipterocarpus is well known for the timber value of its species. The Indian species of the genus are Dipterocarpus bourdillonii and D. indicus, both are endemic to the Western Ghats. The timber of the species has long been exploited for their softwood. Dipterocarpus bourdillonii is a flagship species identified as typical tree in composition and architecture of the low elevational evergreen forests and its population is very low compared to $D$. indicus. As per the CAMP process the species has been given the 'Critically Endangered' status. The future genetic value, the endemicity, the discontinuous distribution, and critically endangered status of the species underline the urgent need for its conservation. Intensive field investigations in Central Western Ghats region shows that $D$. bourdillonii is largely confined to southern part of the Karnataka state (Kodagu or Coorg district) while D. indicus is widely distributed all through the state. Although the area of distribution of the species is restricted to Coorg, it is broken into a few disjunct patches, especially towards the northern half of the district.
\end{abstract}


very low compared to $D$. indicus (Pascal, 1988). As per the CAMP process the species has been given the 'Critically Endangered' status. Ramesh and Pascal (1991) assigned a 'threatened' status and Sasidharan (2003) assigned 'Low Risk' / 'Near Threatened' status to the species.

The future genetic value, the endemicity, the discontinuous distribution, and critically endangered status of the species underline the urgent need for its conservation. With this context, the present study was conducted in Central Western Ghats (Karnataka) to know the distribution, population status and regeneration pattern of the species.

\section{MATERIALS AND METHODS}

Intensive field investigations were undertaken by research team at College of Forestry, Ponnampet in Central Western Ghats region (Karnataka state) as part of the project on "Species recovery of Dipterocarpus bourdillonii and Humboldtia bourdillonii, two critically endangered and endemic species of Western Ghats" funded by Department of Biotechnology, New Delhi. Belt transacts of $250 \mathrm{~m}$ length and $4 \mathrm{~m}$ width were laid in the evergreen and semi evergreen forests in Karnataka state. Presence or absence of Dipterocarpus bourdillonii and D. indicus was observed. Further investigations were carried out to know the potential areas of distribution of Dipterocarpus bourdillonii have been done. The latitude, longitude and elevations of the newly identified locations have been recorded in Global Position System (GPS) (Table 1).

Natural regeneration of $D$. bourdillonii was observed and distance from the mother tree was recorded by using measuring tape. To determine the girth class distribution of the species, the natural regenerates of $D$. bourdillonii were grouped into following regeneration classes for further analysis:

$$
\begin{aligned}
& 0-40 \mathrm{~cm} \text { height-----------------------Class I } \\
& 40-100 \mathrm{~cm} \text { height---------------- --Class II } \\
& >100 \mathrm{~cm} \text { height and }<10 \mathrm{~cm} \text { gbh-----Class III } \\
& >100 \mathrm{~cm} \text { height and } 10-30 \mathrm{~cm} \text { gbh-------Class IV }
\end{aligned}
$$

Regenerates of all the species under the mother tree at different distances were recorded to determine the species richness of the site and species abundance of D. bourdillonii.

\section{RESULTS AND DISCUSSION}

Dipterocarpus bourdillonii is of timber value and a flagship species contributing to the forest composition and, architecture of the low elevational forest type; Dipterocarpus bourdillonii D. indicus - Anacolosa densiflora, described by Pascal (1988). Intensive field investigations in Central Western Ghats shows that $D$. bourdillonii is largely confined to southern part of the Karnataka state (Kodagu or Coorg district) while $D$. indicus is widely distributed all through the state of Karnataka.

Although the area of distribution of the D. bourdillonii is restricted to Coorg district, it is broken into a few disjunct patches, especially towards the northern half of the district. Currently the species was recorded along streams and in some inaccessible areas of Marigundi and Kadamakkal forests in Pushpagiri Wildlife Sanctuary, Coorg at an elevation range of less than $300 \mathrm{~m}$ above MSL. According to Ramesh and Pascal (1991), although the area of distribution of $D$. bourdillonii extends from Coorg (Karnataka) southwards, it is broken into a few disjunct patches especially towards the northern half of its distributional area. 
In the present study, as of now only fourteen individuals of the species are identified in the entire state of Karnataka and their distribution is broken into three patches (populations) within the distance of 7-8 km in the District. Ramesh and Pascal (1997) provided a distribution map of the species based on specimens preserved in herbaria, which confirms the discontinuous distribution. Based on the population status, Ramesh and Pascal (1991) assigned a 'threatened' status and Sasidharan (2003) assigned a 'Low Risk' / 'Near Threatened' status to the species. The details of distribution of $D$. bourdillonii population in Marigundi and Kadamakkal forests of Pushpagiri Wildlife sanctuary Coorg is given in Table 1.

Table 1: GPS (Global Position system) coordinates of area of distribution of Dipterocarpus bourdillonii populations in Central Western Ghats

\begin{tabular}{llll}
\hline Location & $\begin{array}{l}\text { Latitude } \\
(\mathrm{N})\end{array}$ & $\begin{array}{l}\text { Longitude } \\
(\mathrm{E})\end{array}$ & Elevation $(\mathrm{m})$ \\
\hline Marigundi & $12^{0} 37^{\prime} 46.4^{\prime \prime}$ & $75^{0} 38^{\prime} 85.2^{\prime \prime}$ & 176 \\
Kadamakkal A & $12^{0} 32^{\prime} 53^{\prime \prime}$ & $75^{0} 39^{\prime} 57.2^{\prime \prime}$ & 237 \\
Kadamakkal B & $12^{0} 02^{\prime} 026^{\prime \prime}$ & $75^{0} 18^{\prime} 008^{\prime \prime}$ & 271 \\
\hline
\end{tabular}

Number of $D$. bourdillonii regenerates increases as the distance increases from base of the mother tree and maximum number (20) of regenerates was found at $10-15 \mathrm{~m}$ distance, later it stated to decrease (Fig. 1). As the D. bourdillonii seeds are winged and they are wind dispersed, it is clear from the study that the seeds fall at certain distance from base of the tree. It results in less number of regenerates at the base and more at some distance from the mother tree. This may also be due to the locality factors like topography, slope etc.

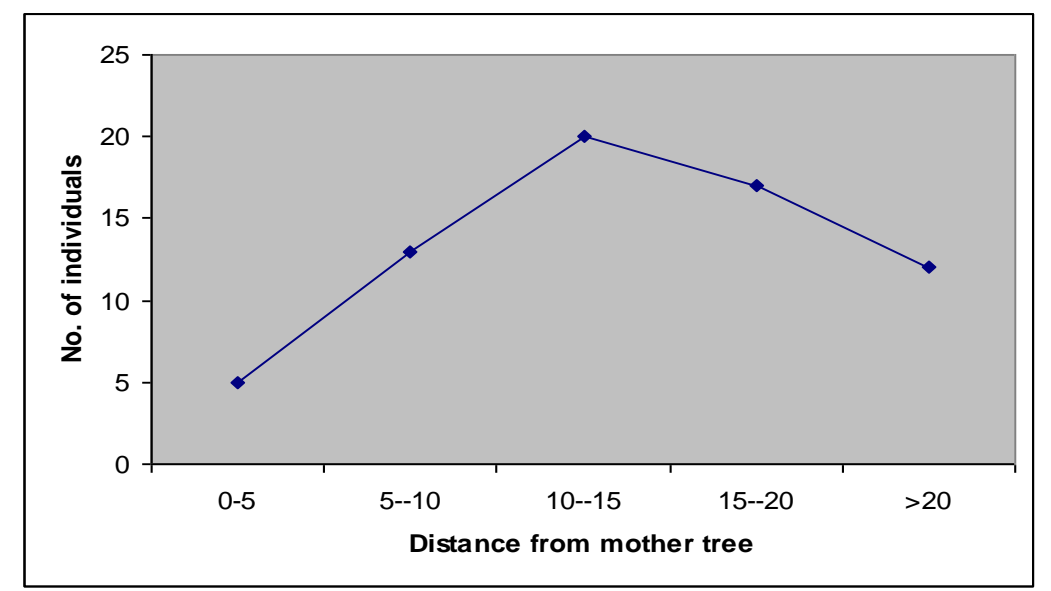

Figure 1: Number of D. bourdillonii regenerates v/s distance from the mother tree

Girth class distribution of D. bourdillonii regenerates shows that the highest per cent (33.3\%) of regenerates are of Class II and it was followed by Class I (28.6\%) (Fig. 2). Class IV regenerates were absent in the study, it may be due to highest mortality rate in this Class. 
Number of species (species richness) under the mother tree was gradually increased as the distance increases from the base. This may be due to shade and also allellopathic effect of mother tree. The number of D. bourdillonii regenerates was higher at 10-15 $\mathrm{m}$ distance from the base of the mother tree.

In the present study Humboldtia brounensis was seen as the most dominant associate species o f D. bourdillonii regenerates (Table 2).

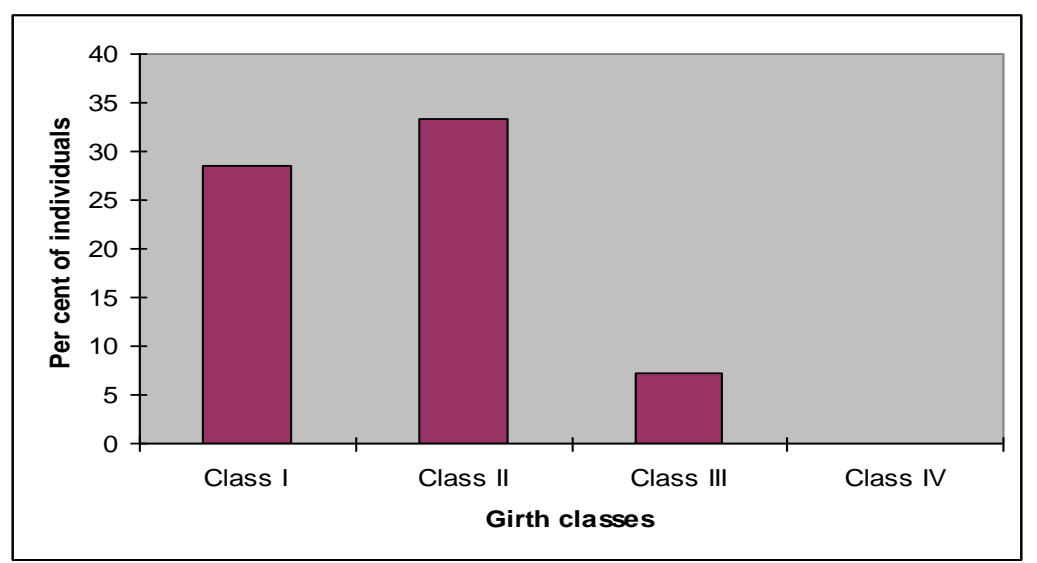

Figure 2: Girth class distribution of Dipterocarpus bourdillonii

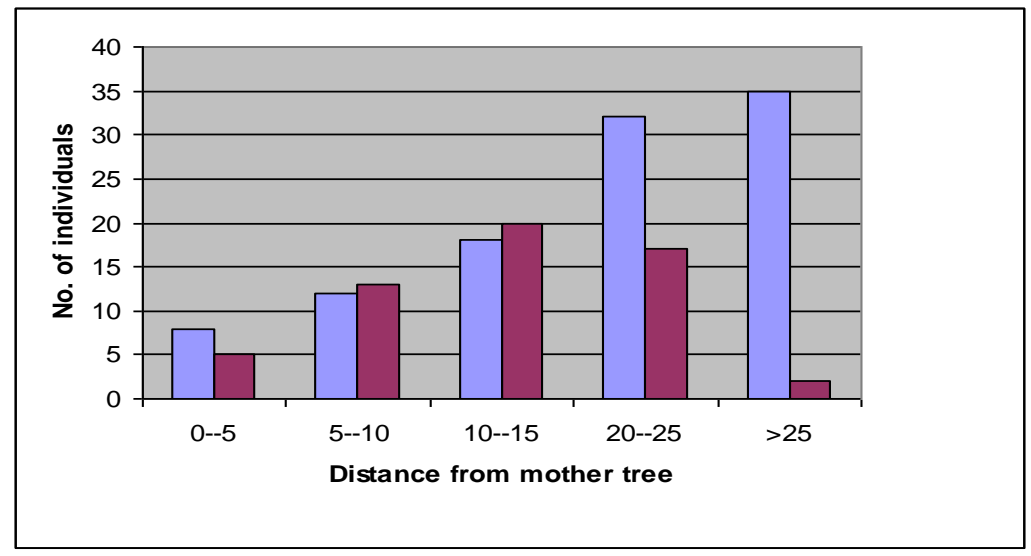

Figure 3: Species richness, number of $D$. bourdillonii regenerates v/s Distance from mother tree

Table 2: List of 10 dominant associate species of Dipterocarpus bourdillonii

\begin{tabular}{ll}
\hline Species & Rank \\
\hline Humboldtia brounensis & 1 \\
Nothopegia bedodmei & 2 \\
Hopea ponga & 3 \\
Tabernaemontana heyneana & 4 \\
Lia indica & 5 \\
Aporusa lindeyana & 6 \\
Vateria indica & 7 \\
Cinnamomum malabathrum & 8 \\
Sterculia alata & 9 \\
Garcinia gummi-gutta & 10 \\
\hline
\end{tabular}




\section{CONCLUSION}

Dipterocarpus bourdillonii is a flagship species identified as typical tree in composition and architecture of the low elevational evergreen forests and its population is very low compared to $D$. indicus. As per the CAMP process the species has been given the status of 'Critically Endangered'. Currently the species is recorded only along streams and in some inaccessible areas of Marigundi and Kadamakkal forests in Pushpagiri Wildlife Sanctuary, Kodagu at an elevation of less than $300 \mathrm{~m}$ in Central Western Ghats. The natural regeneration of the species is poor due to locality factors. The information from this present study on distribution, population status and regeneration pattern may helps to discuss together with possible strategies for implementing in situ and ex situ conservation.

\section{ACKNOWLEDGEMENT}

We thank the Department of Bio-Technology (DBT), Government of India for providing the fund for the project and we also thank Dr. Swarupanandan, Project Co-ordinator, KFRI, Kerala.

\section{REFERENCES}

Kaveriappa and Shetty, B.V., 2001. Biodiversity of Western Ghats with special reference to conservation of plant diversity at Kaiga. An International Journal of Nuclear Power 15 (1): 40-42.

Pascal, J.P., 1988. Wet evergreen forests of Western Ghats of India: Ecology, structure, floristic composition and succession. Travaux de la Section Scientifique et Technique, Tome XX bis, Institute of Francais de Pondicherry. p.345.

Pascal, J.P. and Pelisser, R., 1996. Structure and floristic composition of a tropical evergreen forests in south west India. Journal of Tropical Ecology, 12 (2): 191 - 214.

Ramesh, B.R. and Pascal, J.P. 1991. Distribution of endemic arborescent evergreen species in the Western Ghats. Pages 20 - 29. In: Karunakaran, C.K. (ed.). Proc. Symposium on Rare endangered and endemic plants of the Western Ghats. Kerala Forest Department Wildlife wing, Thiruvananthapuram

Ramesh, B.R. and Pascal, J.P., 1997. Atlas of endemics of the Western Ghats (India): Distribution of tree species in the evergreen and semi-evergreen forests. Institute of Francis de Pondicherry.

Robinson, M., 2008. The Tropical Rain Forests. The Regents of the University of Michigan.

Sasidharan, N., 2003. Red listed threatened tree species in Kerala: A Review. In: Jose Kallarackal, J., Swarupanandan, K. and Sharma, J.K. (eds.). Conservation and research needs of the Rare endangered and threatened (RET) tree species in Kerala part of the Western Ghats. Proc. Workshop. KFRI, Peechi, $1-12$.

WCMC, 1992. Global Biodiversity: Status of the Earth's Living Resources. World Conservation Monitoring Centre; Chapman and Hall, London, UK..

Whitmore, T.C., 1984. Tropical Rain Forests of the Far East, $2^{\text {nd }}$ ed. Oxford: Oxford University Press. 